\title{
Decir el propio género. Feminidades, usos del género gramatical y nombre propio*
}

Nayla Luz Vacarezza**

\section{Resumen}

Basado en la lectura crítica de entrevistas en profundidad, este artículo ofrece un análisis acerca del modo en que las feminidades trans y no trans (o cis) se producen performativamente a través del uso repetido del género femenino gramatical en el discurso autorreferencial y también por medio de la utilización de un nombre propio femenino en su vida cotidiana. En un momento histórico de profundos cambios sociales y culturales relacionados con el reconocimiento, en el año 2012, de la identidad de género de las personas trans en la Argentina (Ley 26743), se examina también el marco legal restrictivo para la asignación de los nombres propios y se analizan las particularidades sociales $e$ históricas del nombre trans. Se utilizan para el análisis conceptos de la teoría de la performatividad del género elaborada por Judith Butler, en diálogo con conceptualizaciones del campo de los Estudios Transgénero.

Palabras clave: Feminidades, Género, Performatividad, Lenguaje.

\footnotetext{
* Recebido em 18 de março de 2016, aceito em 09 de outubro de 2017.

** Investigadora del Consejo Nacional de Investigaciones Científicas y Técnicas de Argentina (CONICET). Instituto de Investigaciones Gino Germani - Facultad de Ciencias Sociales, Universidad de Buenos Aires, Buenos Aires, Argentina. nayla.luz@gmail.com.
} 
Telling One's Gender. Femininities, Uses of Grammatical Gender and a Name of One's Own

\begin{abstract}
Based on a critical reading of in-depth interviews, this article offers an analysis of the way in which trans and non-trans (or cis) femininities are performatively produced, through the repeated use of grammatical feminine gender in self-referential speech and through the use of a feminine name in their daily lives. At a time of profound social and cultural changes related to the recognition in 2012 of the gender identity of transgender people in Argentina (Law $n^{\circ}$ 26743), this article also examines the restrictive legal framework to give names as well as the social and historical particularities of trans names. Concepts from the theory of gender performativity developed by Judith Butler are used for this analysis, in dialogue with conceptualizations from the field of Transgender Studies.
\end{abstract}

Keywords: Femeninities, Gender, Performativity, Language. 
En este artículo se analiza el modo en que las feminidades trans y no trans (o cis) se producen performativamente en la acción repetida de posicionarse como sujetos de género femenino en el lenguaje: a través del uso del género gramatical femenino en el discurso autorreferencial y también por medio de la utilización de un nombre propio femenino en su vida cotidiana. En cuanto a los usos del género gramatical, se da cuenta en forma crítica de la especificidad de la posición de enunciación femenina y de las normas socioculturales que hacen al desprecio o la autorización de esos posicionamientos según sean encarnados por personas trans o no trans. También se analizan los modos en que la rigidez del binarismo del género gramatical propio del idioma castellano es desafiada de distintos modos por algunas entrevistadas trans. En relación con los nombres propios, se interroga el marco legal restrictivo que los regula en la Argentina y se analizan las particularidades sociales e históricas del nombre trans.

Estas reflexiones se basan en una lectura, informada por la teoría de la performatividad del género de Judith Butler, de un corpus de 30 entrevistas en profundidad con personas adultas jóvenes residentes en la Ciudad Autónoma de Buenos Aires y su Área Metropolitana. Todas las entrevistadas se expresan $e$ identifican, en su vida cotidiana, de formas socialmente consideradas femeninas. Dada la complejidad de las posiciones subjetivas, en el estudio se recurrió a una distinción preliminar entre "feminidades trans" (que no se identifican con el sexo/género asignado en el nacimiento) y "feminidades no trans" (o "cis", que se identifican con el sexo/género asignado). ${ }^{1} \mathrm{La}$

${ }^{1} \mathrm{El}$ corpus de entrevistas fue construido para una investigación doctoral (Vacarezza, 2015). Una versión preliminar del análisis que aquí se presenta forma parte de dicha tesis. En todos los casos se utilizan las categorías identitarias con las que se identifican las entrevistadas, pero se han cambiado sus nombres y otros datos sensibles para preservar la confidencialidad y su anonimato. Agradezco a cada una de las entrevistadas por la generosidad en el diálogo y a Barbara Sutton por el apoyo, la lectura y los valiosos comentarios que acompañaron la elaboración de este artículo. 
distinción entre subjetividades cis y trans, acuñada en ámbitos activistas y académicos trans, resulta central para el análisis propuesto, ya que permite advertir procesos de naturalización, jerarquización y distribución diferencial de privilegios sociales entre una y otra posición (Serrano, 2007; Stryker, 2008; Cabral, 2009, 2014; Enke, 2012; Aultman, 2014).

En su conjunto, el análisis que se presenta contribuye a la comprensión de los procesos de jerarquización entre personas trans y no trans en un momento histórico de profundos cambios sociales y culturales relacionados con el reconocimiento de la identidad de género de las personas trans en la Argentina. La pionera Ley 26743 de Identidad de Género, sancionada en la Argentina en 2012, garantiza el derecho a rectificar los datos registrales asociados con la identidad de género (nombre y sexo) mediante un trámite administrativo ágil, que no requiere del sometimiento a diagnósticos patologizadores ni a ningún tipo de modificación corporal y, a la vez, garantiza el acceso a la salud integral, incluyendo el acceso a tratamientos hormonales y quirúrgicos gratuitos para quienes los demanden. ${ }^{2}$

En un escenario histórico en el cual -tanto a nivel regional como mundial- se despliegan grandes controversias en torno a la regulación legal de la identidad de género, las luchas por el reconocimiento social pleno de las personas trans se libra de manera efectiva en el terreno de los lenguajes legales y burocráticos, pero también en el habla cotidiana, al momento de nombrarse, de hablar de sí mismos/as y de ser reconocidos/as e interpelados/as por otros/as en tanto sujetos generizados. Este artículo transita, entonces, una reflexión acerca del reconocimiento comprendido como un aspecto fundante en la constitución de las subjetividades sociales, pero también como un asunto central en las disputas políticas contemporáneas en torno al reconocimiento

2 Sobre la Ley de Identidad de Género, véase, entre otros, Cabral (2012), Farji Neer (2013) y Litardo (2013). 
de las diferencias sociales. ${ }^{3}$ Específicamente, se retoma la perspectiva crítica elaborada por Judith Butler para reflexionar acerca de los modos en que los marcos normativos que limitan el reconocimiento de las subjetividades sociales generizadas son reforzados, tensionados y transformados tanto a nivel legal como en la vida cotidiana.

\section{Feminidades y usos del género gramatical}

Desde la perspectiva performativa elaborada por Judith Butler, podría decirse que el sujeto se produce como tal por medio de la acción repetida de posicionarse en un lenguaje cuyas normas exigen modos coherentes de generización gramatical. El recononcimiento social como sujeto depende de la inscripción dentro de un lenguaje que prescribe modos coherentes $e$ incoherentes de generización. Estos usos del género gramatical constituyen una forma de estilización de sí porque se trata de un modo de presentarse ante otros/as que implica, al mismo tiempo, una participación obligatoria en el régimen de género. Para dar cuenta de este procedimiento forzoso de generización que se realiza en el lenguaje, Judith Butler, en El género en disputa (2007), recurre a un ensayo de Monique Wittig titulado "La marca del género" (2006). Allí Wittig sostiene que los sujetos no pueden adquirir significado dentro del lenguaje por fuera de la gramática del género. Acerca de esto, Butler (2006:78) sostiene que "[p]ara Wittig, el género no solo designa a personas -las «califica», por así

${ }^{3}$ La cuestión del reconocimiento ha sido objeto de sustantivas reflexiones en el ámbito de la teoría social, la teoría crítica y las teorías feministas en las últimas décadas. Aunque excedería los propósitos de este artículo profundizar en esas reflexiones conceptuales, podría decirse que han sido animadas desde la década de los noventa por agudas disputas políticas en torno al multiculturalismo y la diversidad, la exclusión social y el rol de las izquierdas y los nuevos movimientos sociales en el capitalismo contemporáneo. Las contribuciones de Charles Taylor (1994) y Axel Honneth (1995) resultan fundamentales a este respecto, así como el debate que mantuvieron Nancy Fraser y Judith Butler en la revista New Left Review durante el año 2000 (2016). 
decirlo- sino que constituye una episteme conceptual mediante la cual se universaliza el marco binario del género".

En castellano, el género gramatical se constituye como un sistema de oposiciones cuyo uso correcto exige la concordancia de género entre los sustantivos, adjetivos, artículos y pronombres. El proceso de apropiación del aparato formal de la lengua por parte del enunciador implica entonces, necesariamente, adquirir una posición estable dentro de ese par binario.

Uno de los criterios de inclusión de las entrevistadas dentro del universo de estudio fue que estas utilizaran de forma corriente el género femenino gramatical en su discurso autorreferencial. Y así lo hacen todas nuestras interlocutoras, trans y no trans. La primera persona del singular (el "yo") que tiene preeminencia en el discurso autorreferencial de la entrevista en profundidad es de género neutro, pero de todos modos, y como sostiene Monique Wittig (2006:106), “... cuando hay un hablante en el discurso, cuando hay un «yo», el género aparece". La posición generizada de nuestras interlocutoras trans y no trans se establece cuando ellas usan en su discurso adjetivaciones para sí mismas, artículos y otros pronombres femeninos, como es posible observar a continuación:

...siempre estoy impecable, arreglada, siempre fui fina y elegante para vestirme (...) nunca me vas a ver desarreglada... (Débora, travesti, 25 años). ${ }^{4}$

...recibía castigo afuera por ser distinta (...) vivía todo el tiempo angustiada... (Florencia, mujer trans, 33 años).

...a veces una también se cansa de hacer las cosas de la casa, atender los chicos, y se cansa una (Soledad, mujer no trans, 27 años).

4 El destacado, aquí y en los casos siguientes, me pertenece. 
...quizás ella me conocía más que yo a mí misma... (Belén, mujer no trans, 26 años).

Usos "correctos" del género gramatical equivalentes a los citados se repiten a lo largo de todo el corpus de entrevistas. Cabría, entonces, preguntarse ¿de qué se trata esta insistente y meticulosa regularidad de las marcas del género gramatical? ¿Qué podría decirse sobre el uso coherente y esperable del género gramatical en el habla cotidiana cuando es tan constitutivo de la subjetividad $y$, a la vez, tan frecuente $e$ incesante, que tiende a pasar desapercibido?

En el libro Lenguaje, poder e identidad (2004), Judith Butler se "apropia indebidamente" del concepto psiconalítico de forclusión para dar cuenta de una operación de censura que forma al sujeto que habla y asegura que ese proceso formativo nunca se complete del todo sino que deba ser reafirmado una y otra vez. Las operaciones de exclusión que forman al sujeto son entendidas, en este sentido, como modalidades productivas del poder, porque el sujeto emerge como resultado de dichas exclusiones (Butler, 2004:227).

Podría decirse que los usos coherentes del género femenino gramatical y la consecutiva exclusión de las desinencias masculinas se encuentran entre los rasgos más poderosos que producen performativamente la ilusión de una identidad de género sustancial y permanente. Pero no por eso deberíamos afirmar que existe un sujeto volitivo que de modo intencional adopte las desinencias femeninas y excluya las masculinas. Por el contrario, sería más acertado decir -siguiendo la propuesta de Butler- que el sujeto femenino de la enunciación emerge a través de la reiteración de una exclusión que opera como norma implícita. En este sentido, Leticia Sabsay (2007:71-72) sostiene que la adjetivación y el uso de pronombres por parte de lo que aparece en el lenguaje como un sujeto sustantivo no es en realidad más que un momento de cristalización de una práctica reiterada cuya estructuración corresponde a normas que son la condición de posibilidad para la emergencia del sujeto y de su 
singularidad. Esa práctica incesante de exclusión constituye, entonces, la condición para la emergencia de una posición enunciativa generizada coherente, desde la cual se articula no solo el sentido de sí misma en tanto sujeto sino también el reconocimiento social en tanto tal.

Los sujetos de habla generizados -trans y no trans se forman y hacen socialmente inteligibles a través de la repetición incesante de las convenciones relativas al género gramatical. Sin embargo, resta reflexionar acerca de las severas normas sociales que autorizan o no a los sujetos para usar esas convenciones y ocupar determinadas posiciones de género en el lenguaje. ¿Qué sujetos pueden ocupar de forma legítima una posición de enunciación femenina y qué normas socioculturales reconocen y aprueban o desautorizan esos posicionamientos?

Feminidades trans, invocaciones "ilegítimas" del género femenino y reconocimiento negado

Las normas lingüísticas formales de coherencia, en lo que se refiere a la asunción del género gramatical, no funcionan en el vacío, sino que se acoplan con normas sociales e históricas que regulan qué sujetos pueden ser reconocidos y ocupar legítimamente las posiciones generizadas. En el caso de las feminidades trans, la asunción de una posición femenina en el lenguaje puede ser algo trabajoso, ya que muchas veces esta es socialmente censurada y no reconocida como legítima, por contradecir la norma social y lingüística que dicta que, en el caso de las personas, la "variación [de género] refleja una diferenciación sexual” (García Negroni, 2011:180).

Las feminidades trans, como el resto de las feminidades, invocan las convenciones del género gramatical en su habla cotidiana. Pero, a diferencia de las feminidades que no son trans, no están aún del todo autorizadas por las convenciones sociales y culturales para hacerlo. La posición generizada que asumen las feminidades trans en el lenguaje es con frecuencia despreciada, se le niega el reconocimiento social $\mathrm{y}$, por lo tanto, su viabilidad 
como seres sociales reconocibles se ve amenazada o al menos obstaculizada.

Nuestras interlocutoras trans narran distintos disgustos $y$ padecimientos asociados con el rechazo hacia su posición femenina en el lenguaje. Juana, una mujer trans de 31 años, dice que "es molesto" cuando se refieren a ella usando un pronombre masculino:

...ya me definí muy claro por lo femenino, digamos, ya logré esto, hablo así, entonces no da que me llamen él, yo ya crucé una barrera de la feminidad que adopto y que tengo y la verdad que me quiero quedar con esto y es molesto que me hablen así.

$\mathrm{Su}$ sentido de sí misma, y de su género, parece estar fuertemente arraigado en el lenguaje. La utilización por otros de la tercera persona singular masculina para referirse a ella le resulta inaceptable y también hiriente ("no da que me llamen él, [...] es molesto que me hablen así"). Sin embargo, esa forma de ser inscripta como objeto de la alocución ajena cumple performativamente con el objetivo de ubicarla e inmovilizarla en la posición de género asignada (masculina), al tiempo que le recuerda que no está autorizada a ocupar ese otro lugar generizado que siente como propio (el femenino).

Ser interpelada en el lenguaje en tanto sujeto masculino constituye una forma de desprecio que muchas veces se presenta al mismo tiempo como una amenaza, más o menos certera, de otras formas de violencia:

... mi hermano me decía siempre [sube el tono de voz] isi yo te veo vestido de mujer te paso el auto por encima! [silencio corto] o sea... fuerte... me hacía mierda que me hablara así (Florencia, mujer trans, 33 años).

Judith Butler (2004:17) sostiene que "el daño lingüístico parece ser el efecto no solo de las palabras que se refieren a uno sino, también, del tipo de elocución, de un estilo -una disposición 
o un comportamiento convencional- que interpela y constituye a un sujeto". En este sentido, el poder hiriente del discurso del hermano de Florencia no radica solamente en el contenido de lo dicho (utiliza un adjetivo masculino para referirse a ella, profiere una amenaza) y en el tono que Florencia recrea en su alocución. El odio que expresa el hermano no se inicia con sus palabras, sino que esa actitud se inscribe y asume la fuerza de una convención social de desprecio y no reconocimiento hacia quienes no respetan las normas sociales de correlación obligatoria entre sexo y género.

En el enunciado "me hacía mierda que me hablara asi"" puede advertirse una subjetividad "lingüísticamente vulnerable" (Butler, 2004), es decir, que puede ser herida por las palabras. Lo que su hermano le decía una y otra vez ("siempre") a Florencia establecía - $\mathrm{O}$ al menos buscaba establecer- de manera performativa los términos en que ella sería reconocida, y estos términos son violentos porque tienen el efecto de hacerla sentir como un desecho. Al recibir las palabras del hermano, Florencia se siente expulsada de su condición de ser humano. Y, además, ella recibe una amenaza que, en tanto acto de habla, afirma la inminencia de otro acto ("te paso el auto por encima"), que puede producirse o no, pero que cumple el efecto de atemorizar y dañar a quien la recibe.

Ahora bien, a la vista del segmento que sigue, cabe preguntarse: ¿qué especificidad tiene el hecho de que el no reconocimiento de la posición generizada de una mujer trans sea ejercido por agentes estatales? Florencia da cuenta de las formas de desprecio hacia su género que ocurrían en las comisarías cuando aún estaban vigentes en la Ciudad Autónoma de Buenos Aires los edictos policiales que permitían la detención de las personas trans al circular por la vía pública: ${ }^{5}$

\footnotetext{
5 Vigentes hasta 1998 en la Ciudad Autónoma de Buenos Aires, los edictos policiales eran un instrumento que permitía a la policía reprimir actos no previstos por el Código Penal con detenciones y arrestos. Dos edictos $\left(2^{\circ} \mathrm{F}\right.$ y $\left.2^{\circ} \mathrm{H}\right)$ criminalizaban a travestis y trans, porque penaban a quienes "se exhibieren en la
} 
... en aquel momento el travestismo era un delito y te levantaban y te llevaban preso, era todo lo que te podés imaginar, patético, espantoso, y cuando te llevaban la violencia era tremenda (...) recuerdo una vez que mi madre me había llevado comida [a la comisaría] (...) y dijo tienen a mi hija detenida y quiero saber cuándo va a salir... ¿Cómo se llama su hija? Acá no tenemos ninguna mujer detenida le decían (...) y encima le decían, cuusted sabe que su hijo...? Todo el tiempo me trataban de varón... entonces ella les decía, para mí es mi hija (...) la policía le decía cómo va a aceptar semejante cosa, ¿un hijo que se vista de mujer?, ¿en qué cabeza cabe?

En la escena narrada el desprecio hacia la condición trans proviene y es legitimado por el Estado. En la disputa sobre el género de la persona detenida entre la madre y los agentes policiales del Estado, se advierte hasta qué punto el lenguaje (el género gramatical, los pronombres), lejos de ser una cuestión formal y superflua, resulta un escenario clave de luchas que atañen al reconocimiento, la calidad de la ciudadanía, el trato digno y el respeto de los derechos.

\section{Nuevas posiciones generizadas en el lenguaje}

La lectura del conjunto de entrevistas permite afirmar que las feminidades trans no solo reproducen, sino que también tensionan la normativa gramatical del género cuando crean narrativas de sí mismas en las que evitan, en ciertas circunstancias, utilizar uno de los dos géneros gramaticales o crean nuevas posiciones generizadas en el lenguaje.

La creación de expresiones que evitan la generización es una estrategia que se repite, en especial cuando las entrevistadas trans se refieren a los momentos en que comienzan a vivir su

vía pública con ropas del sexo contrario" y a quienes "públicamente incitaren o se ofreciesen al acto carnal". 
feminidad de una manera abierta y pública. Es eso lo que muestra el siguiente segmento de la entrevista con Juana, mujer trans de 31 años:

\begin{abstract}
... empecé a hablar en femenino cuando me mudé a Buenos Aires (...) y me costaba hablar [por teléfono] con mi familia en Salta, tenía que tener en cuenta que tenía que hablar en masculino o con palabras neutras y era complicado... había llegado a un sonido que era indistinto entre la a y la o... decía hoy estuve todo el día sol*, trabajé todo el día estoy cansad*.
\end{abstract}

Juana crea un sonido "indistinto entre la a y la o" para poder hablar con su familia cuando todavía no había decidido compartir con ellos/as su posicionamiento femenino. Esa creación surge de la necesidad de encontrar un lugar desde el cual hablar, y aquí la transcribimos con un asterisco (*) para señalar la imposibilidad de dar cuenta de ese sonido por medio de la escritura alfabética.

Suele decirse que al apropiarse del aparato formal de la lengua el "yo" se representa a sí mismo, pero eso no sería del todo correcto porque el lenguaje es constitutivo de ese "yo", le pone límites y lo obliga a generizarse. A pesar de ello, como se evidencia en lo dicho por Juana, el lenguaje también puede ser el ámbito para la costosa creación de una posición nueva, precaria e imposible de inscribir en el sistema alfabético. ${ }^{6}$

6 Distintas estrategias políticas se dirigen a tensionar el lenguaje para evitar su sesgo binario y androcéntrico. La forma más corriente es el "desdoblamiento genérico", es decir, evitar el uso del masculino como universal y, en su lugar, utilizar tanto el masculino como el femenino. Las apuestas por el uso de la arroba (@), la equis (x) o el asterisco (*), por su parte, buscan ir más allá e inscribir en el lenguaje escrito posiciones de género que exceden el binario de género. Pero estas estrategias son difícilmente trasladables al lenguaje oral, donde comienzan a utilizarse las vocales "e" y la "i" en reemplazo de la "a" y la "o", las desinencias de género más comunes en castellano. 
Si bien, como se dijo, las posiciones de enunciación coherentes son el efecto de exclusiones (del otro género gramatical, de los usos incoherentes del género), el sujeto no necesariamente está limitado a ser un efecto exitoso de ellas. La redefinición de las líneas que delimitan lo correcto de lo incorrecto y lo normal de lo anormal es una actividad que el lenguaje también habilita. En el caso de Juana, la reformulación de sí misma como sujeto de lenguaje a través del uso de formas genéricamente neutras y de nuevos sonidos que no coinciden con los normativos, son actos de habla que la transforman a ella y que transforman también su contexto: "Ese momento en el cual un acto de habla que no tiene una autorización previa sin embargo asume la autorización en el curso de su realización puede anticipar e instaurar contextos diferentes para su futura recepción" (Butler, 2004:257). Juana funda un lugar para sí cuando, con esfuerzo, rompe con su obligada generización masculina en el lenguaje, evitando el uso de construcciones lingüísticas que impliquen un posicionamiento subjetivo generizado:

...yo buscaba palabras para no generizarme... o sea, estoy cansado no decía, decía me cansé... buscaba palabras para no masculinizarme y no sentirme yo mal (...) cuando hablaba con mi mamá, yo no podía tratarme de él, entonces (...) le decía (...) después fui al shopping y estuve con mis amigos y salí y no decía volví borracho; decía volví re en pedo... digamos, siempre buscando palabras, que después me salían natural, de tanto experimentarlo (...) era buscar cómo decirlo también...

En el segmento, parece no importar tanto cómo Juana es tratada por los demás sino el hecho de que ella procuraba establecer un trato respetuoso y ético consigo misma ("yo no podía tratarme de él"). El problema no parece ubicarse en torno a la opción de hablar o no hablar o de revelar u ocultar su posicionamiento de género, sino en torno a cómo hablar y cómo lograr una estilización generizada de sí misma en el lenguaje ("buscar cómo decirlo"). Su respuesta y las de otras entrevistadas 
trans ante los límites que impone el binario de género surgen de una búsqueda y de un proceso de experimentación que resulta en la producción de usos no convencionales del lenguaje; intersticios desde los cuales alterar la rigidez de las normas que delimitan lo que es socialmente reconocible.

\section{Sexo, género y nombre propio}

El nombre de las personas, comúnmente llamado "nombre de pila", se encuentra regulado por severas normas sociales y culturales que alcanzan, incluso, el plano legal. Desde una perspectiva performativa, podría decirse que el nombre es también constitutivo de la subjetividad generizada, ya que a través de la experiencia constante de ser nombrado y, luego, de nombrarse, el sujeto adquiere una posición a la vez singular y genérica dentro del orden social binario de los géneros.

El nombre se impone a la criatura recién nacida y es el primer signo de que existe en el lenguaje y en una situación pasiva con respecto a él, porque el sujeto es, desde el principio, nombrado por otros. El nombre propio no describe nada, no es verdadero ni falso, sino que de modo performativo establece al sujeto en la sujeción a ese nombre, y a la vez, en la sujeción a un régimen identitario binario y heteronormativo que vincula de manera obligatoria al sexo con el género. En la experiencia constante de ser nombrado y de nombrarse, el sujeto es puesto en relación con su sexo y adquiere un estatus reconocible dentro del régimen binario del género.

En la Argentina, la Ley 18248 de Nombre de las Personas prohíbe la elección de nombres que "susciten equívocos respecto del sexo de la persona a quien se impone". Los nombres de pila, en consecuencia, son clasificados como masculinos o femeninos, y deben ser impuestos en concordancia con el sexo asignado a la criatura. En las tramas médico-legales de identificación de las personas por parte del Estado, el sexo asignado según criterios biomédicos actúa, entonces, como instituyente obligatorio del género (Litardo y Rada Schultze, 2010). 
Michel Foucault, en La voluntad de saber (2008), sostuvo que el sexo funciona como bisagra de las dos direcciones en las que se desplegó el biopoder en la modernidad. Siguiendo estas indicaciones, es posible ubicar, por un lado, el control totalizante que mantiene la ficción heterosexista de las poblaciones divididas en dos sexos supuestamente complementarios para la reproducción, y por el otro, el control individualizante de la identidad que anuda el sexo con el género y el nombre propio. Dicho poder individualizante es constitutivo de las subjetividades porque el sujeto emerge y se forma bajo el signo del sexo al que fue asignado. Puede decirse, siguiendo a Butler (2005), que la asunción del sexo/género asignado se impone también a través del nombre propio y es obligada desde el momento en que el sujeto emerge como tal. Se trata de un modo de subjetivación dominante que procede de manera excluyente y diferencial produciendo, al mismo tiempo, los sujetos apropiadamente generizados (toda vez que sexo, género y nombre se alinean según la normativa) y también los sujetos que quedarán en los márgenes de esa norma.

Judith Butler sostiene que el nombre inaugura y alimenta la existencia lingüística: "Una vez que hemos recibido el nombre propio, estamos sujetos a ser llamados de nuevo. En este sentido, la vulnerabilidad de la llamada constituye una condición constante del sujeto hablante" (Butler, 2004:56-57). El nombre es, para Butler, una forma de interpelación autoritaria que resulta constitutiva para la formación del sujeto y para su posibilidad de existencia y acción social. Resulta casi imposible imaginar un sujeto al margen de un nombre y de una posición generizada en el lenguaje, porque esas son las condiciones de posibilidad para hablar, para dirigirse a otros y también para constituirse en objeto del reconocimiento, el habla y la interpelación ajena.

Dar un nombre es, antes que nada, un acto unilateral. Pero quien nombra ha sido, a su vez, nombrado, y su poder de nombrar se deriva del hecho de haber sido nombrado. Entonces, en el acto de darle un nombre a un ser humano se actualiza la eficacia performativa de una convención reiterada: la de nombrar al sujeto en concordancia con el sexo que le fue asignado. La Ley 
de Nombre de las Personas refuerza el binario al establecer un marco restrictivo según el cual un campo de nombres posibles se delimita en el momento en que se asigna el sexo a la criatura humana. De modo que la elección de quien nombra no puede interpretarse como un acto volitivo absoluto sino como el efecto de esa restricción previa.

En una de las entrevistas, una mujer no trans se refiere a los nombres que su padre y su madre imaginaban para ella antes de que naciera: "Mi nombre de varón iba a ser Juan Ignacio" (Carina). Con esa afirmación -una perífrasis verbal convertida en variante del condicional- ella pone en palabras lo que fue un posible futuro de su pasado. El sexo asignado al nacer canceló aquel futuro imaginado por otros para ella, y que estaba asociado con ese nombre masculino que finalmente no fue suyo. Digamos que, de acuerdo al sexo asignado, no solo cambia el nombre sino también, con él, el estatus social y los futuros imaginados para ese sujeto.

Alelí, una mujer no trans de 24 años, también narra la curiosa historia de restricciones que precede a su nombre:

... no me podían poner Alelí porque Alelí es un sustantivo masculino y en ese momento justo de la historia del Registro Civil argentino ese nombre que es un sustantivo masculino no se lo podían poner a las nenas solo, me tenían que agregar un nombre que denotara el sexo y que tenía que ir adelante, que fuera femenino.

Cabría preguntarse el porqué de la insistencia administrativa en hacer indubitable el carácter femenino del nombre. La tenacidad con que necesita repetirse la norma de generización muestra su arbitrariedad y su carácter no necesario. Debe instaurarse una y otra vez, incluso de maneras hiperbólicas como la relatada por Alelí, porque no perdura por sí misma.

Acatada la restricción impuesta por el sexo asignado, distintas circunstancias son mencionadas por las entrevistadas no trans como determinantes de la elección de su nombre: tradiciones familiares, comunitarias, religiosas, preferencias estéticas $e$ 
historias personales de los adultos actúan como condicionantes de la elección del nombre impuesto al nacer a las mujeres no trans.

Hasta la sanción de la Ley 26743 de Identidad de Género, ese nombre fijado al nacer en relación obligatoria con el sexo asignado resultaba, para el Estado, una identidad civil inmutable que permanecería a lo largo de la vida de la persona y determinaba, a la vez, quién sería un sujeto reconocible para la vida social a la vez que un/a ciudadano/a en el plano jurídico. La matriz de subjetivación excluyente que de forma histórica reguló y jerarquizó el campo de los sujetos instauraba, a la vez, un privilegio fundamental pero pocas veces advertido para las personas no trans. el de nombrarse, ser nombradas y sociojurídicamente reconocidas a través de un nombre de pila y también, en consecuencia, de un género reconocido como propio.

Contradecir los términos que imponían una correlación obligatoria entre el sexo bioanatómico asignado, el género y el nombre a lo largo de toda la vida, como lo hacen las feminidades trans, suponía (y todavía supone, en muchos sentidos) arriesgar el estatuto de una misma como sujeto social y también como ciudadana. Sin embargo, las feminidades trans han tomado (y toman) el nombre que sienten como propio en su vida cotidiana, aun cuando con ello se exponían a ser rechazadas y no reconocidas, por ejemplo, por su familia:

... dejé de frecuentarlos [a un grupo de familiares] porque bueno (...) era hablar por teléfono y hola, ¿cómo te va? y no ser Juana, siempre ser el otro nombre (Juana, 31 años).

... me cerré con mi vieja porque me seguía tratando de Julián y después me mandaba mails como hijito mío, y yo le decía mirá, yo no quiero ser tu hijo, no soy tu hijo, no soy Julián, mi nombre es Rocío, así que seré tu hija Rocío y si no, no seré nada para vos (Rocío, 40 años).

En ese gesto reiterado de afirmarse en su nombre, a pesar del rechazo de los/as familiares y enfrentándose incluso a la posibilidad de cortar los vínculos con ellos/as, se advierte la 
importancia que tiene darse a conocer por un nombre que se ajuste a la propia percepción de sí misma. En los actos insistentes de nombrarse como ellas desean y no como imponen las convenciones sociales, se pone en evidencia que la pretensión jurídica y administrativa de alinear los cuerpos con las categorías sociales y los nombres fracasaba y fracasa, exponiendo su arbitrariedad y su carácter no necesario.

A diferencia de quienes no son trans y cuyo nombre fue impuesto al nacer, entre las feminidades trans que entrevistamos el nombre surge en el momento en que su género empieza a ser expresado ante otros y otras. En algunos casos, el nombre surge en el momento en que ellas empiezan a relacionarse con otras feminidades trans.

... me empecé a contactar con chicas [travestis y trans por internet] (...) y lo primero que me dijeron es, mirá, vos tenés que tener tu nombre... (Rocío, 40 años).

... con ella [una travesti mayor] empecé a ser Lucía, aprendí a tratar a los clientes, a cobrar (...) era mi madre... (Lucía, 22 años).

En el caso de Rocío, una mujer trans de clase media y profesional que empezó a vivir públicamente su género siendo ya adulta, la comunidad que la impulsa a "tener" su nombre es un colectivo online de travestis y mujeres trans. El nombre de Lucía quien inició su transición a los 14 años- también surge de su contacto con otras travestis, pero se trata de otro tipo de comunidades, ligadas al trabajo sexual callejero y al "pupilaje". 7 Pero no siempre el nombre trans surge del contacto con otras

\footnotetext{
7 Josefina Fernández sostiene que el "pupilaje" es "una manera de regular las relaciones entre las travestis en el ámbito del trabajo. Es también el mecanismo a través del cual se socializan las más jóvenes en cuestiones relativas a la prostitución. Intervienen en el pupilaje dos actores: las pupilas y la madre que las tiene a cargo" (2004:94).
} 
feminidades trans. Miranda, una actriz trans de 24 años, narra la historia de su nombre diciendo: “... en mi caso fue una mujer biológica, Gabi, la que me ayudó con el nombre, no tuve madre trans y no tengo madre".

Al no tratarse de nombres impuestos al nacer, podría pensarse que los nombres trans surgen de una elección completamente individual. Pero, como hemos visto, esto es así sólo en parte porque -de un modo similar a lo que sucede en el caso de las entrevistadas no trans- en las narraciones trans el nombre surge de un proceso donde las comunidades de pertenencia y los vínculos sociales y afectivos tienen un rol preponderante.

\section{Nombre trans, interpelación estatal y "violencia administrativa"}

... muchas chicas [trans] muchas veces no iban a hacer trámites sencillos por vergüenza a mostrar el DNI, a mostrar su nombre del documento y por esa vergüenza por ahí dejaban de hacer cosas importantes o hasta se dejaban morir (Moira, mujer trans de 28 años).

Ante la afirmación de Moira, cabe preguntarse ćqué sucede cuando el nombre propio se convierte en una fuente de vergüenza? ¿Qué tipo de subjetividades pueden surgir a partir de un nombre avergonzante que el Estado insistía en repetir, en la Argentina, hasta la sanción de la Ley de Identidad de Género en 2012?

Hasta ese momento, cuando las personas transitaban por instancias administrativas y judiciales del Estado $u$ otras instancias institucionales que se manejan con las identificaciones provistas por el Estado, como el documento nacional de identidad (DNI) y la partida de nacimiento, se reiteraba necesariamente la interpelación fundacional del nombre que anudaba de manera obligatoria el sexo con el género. Una forma de reconocimiento del todo naturalizada para las personas no trans que, sin embargo, negaba el reconocimiento y resultaba avergonzante y excluyente 
para las personas trans que no utilizaban en su vida cotidiana el nombre asignado en el nacimiento.

Para las feminidades trans, constituidas en su subjetividad por esa negación del reconocimiento estatal, llegar a ser reconocidas de manera legal por el nombre que sienten como propio puede tener el carácter de una gesta. ${ }^{8}$ Una hazaña que, aunque a veces se experimente como personal, se enreda con lo colectivo, y que quienes ya contaban con su nombre reconocido en el DNI al momento de realizar la entrevista suelen relatar animadamente.

Judith Butler sostiene que incluso en los formularios, las solicitudes y otros instrumentos del poder burocrático, el nombre se repite, formando las subjetividades y actualizando las interpelaciones generizadas:

El nombre interpelativo puede incluso darse sin hablante, como en los formularios burocráticos, en el censo, en los papeles de adopción, o en las solicitudes de empleo... la difusión burocrática y disciplinaria del poder soberano produce un territorio de poder discursivo que opera sin sujeto pero que produce al sujeto en el curso de su operación (Butler, 2004:62).

El profesor y activista trans Dean Spade (2011), por su parte, sostiene que los sistemas administrativos (los estatales y también los no estatales) se encuentran en gran medida generizados y que esto trae dificultades específicas para las personas trans. Pensemos, como propone Spade, en los servicios de internación hospitalaria y otros servicios médicos (públicos y privados), en los refugios para personas sin vivienda, en las prisiones y en los lugares de detención, etc. En estas y otras múltiples instancias administrativas y burocráticas los sujetos son interpelados $y$

8 No casualmente, uno de los primeros estudios sobre travestismo en la Argentina lleva el título La gesta del nombre propio (Berkins y Fernández, 2005). Véase también la nota "Políticas del nombre", de María Moreno (2016). 
separados según el nombre y también según el género (registrado como "sexo") que figura en las identificaciones provistas por el Estado. Algo que, como han mostrado los estudios hechos por iniciativa de la comunidad travesti-transexual-trans (Berkins; Fernández, 2005; Berkins, 2007), provocaba grandes dificultades para el acceso a los derechos ciudadanos más básicos.

En las conversaciones con las entrevistadas trans, el nombre registrado en el DNI y no adecuado a su identidad de género aparece de modo recurrente como un obstáculo a la hora de acceder al voto, al trabajo, a la educación, a la atención médica y a las condiciones dignas de detención, entre otros derechos.

Ellas narran cómo, de manera inevitable, se han sometido a ser interpeladas por el nombre masculino registrado en el DNI para tener una existencia cívica y social. Se trata de escenas en las cuales han sido sometidas a una visibilidad que no es elegida, que muchas veces resulta avergonzante y que las expone a distintas formas de rechazo y discriminación. Es el caso de Juana, la mujer trans de 31 años ya mencionada, para quien la situación misma de emitir el voto con un nombre que no la identificaba exponía su disidencia genérica y a su vez la borraba, ya que el voto se registraba con un nombre que ella rechazaba: "yo cuando fui a votar no quería que griten mi nombre, obvio que la gente que estaba ahí se daba cuenta de que yo era trava... o no... no sé, pero sí quería un respeto hacia mi nombre".

La fuerza performativa de la interpelación generizada estatal se manifiesta de maneras extremas en la situación de encierro propia del sistema penal, donde las personas trans femeninas permanecen aún en unidades penales masculinas y son víctimas sistemáticas de tratos degradantes. ${ }^{9} \mathrm{El}$ nombre masculino opera,

9 Sobre la situación de las ciudadanas trans presas en la Argentina existen gravísimas denuncias realizadas por organizaciones de derechos humanos. Sin embargo, debido al hermetismo del sistema penitenciario, es muy escasa la información sistemática. Véanse: Comisión Provincial por la Memoria (2012, 2013) y Wayar (2012). 
en el relato de Xoana acerca de su experiencia en la cárcel, como la clave de su borramiento subjetivo:

...es como que el sistema judicial y penal nos quiere desaparecer, borrar, porque piensan que nuestra población es población común, somos un nombre, un nombre masculino (...) entonces para ellos sos un chabón también, entonces ¿qué hacen? Te tratan como tal (Xoana, mujer trans, 29 años).

Tratar a Xoana como "un chabón" desconoce, sin dudas, la obligación ética de reconocer y respetar al otro en su diferencia. Pero, siendo un ámbito estatal, el trato recibido constituye también una forma de degradación de su calidad de persona y de ciudadana.

Distintas estrategias colectivas se han desarrollado con el objetivo de impulsar prácticas de buen trato y reconocimiento del nombre trans antes de la sanción de la Ley de Identidad de Género, que instaura de manera definitiva las condiciones para un trato digno hacia las personas trans. ${ }^{10}$ Estas importantes inciativas fueron llevadas adelante por activistas y organizaciones en distintas instituciones públicas, entre ellas ministerios, universidades nacionales $\mathrm{y}$ facultades, que reconocieron el derecho de las personas a ser tratadas por el nombre que reconocían como propio. ${ }^{11}$

\footnotetext{
${ }^{10}$ El artículo 12 de la Ley de Identidad de Género establece parámetros para el "trato digno" en los cuales el nombre de pila tiene un rol fundamental: "Deberá respetarse la identidad de género adoptada por las personas (...) que utilicen un nombre de pila distinto al consignado en su documento nacional de identidad. A su solo requerimiento, el nombre de pila adoptado deberá ser utilizado para la citación, registro, legajo, llamado y cualquier otra gestión o servicio, tanto en los ámbitos públicos como privados".

${ }^{11}$ Entre las iniciativas destacamos la pionera Resolución $n^{\circ}$ 2359/07 del Ministerio de Salud de la Provincia de Buenos Aires, que reconoció en 2007 el derecho al respeto de la identidad de género. La resolución fue impulsada por el Movimiento Antidiscriminatorio de Liberación y por su referente, Diana Sacayán. La identidad de género fue también reconocida en 2010 por resolución del
} 


\section{Reconocimiento estatal del nombre trans}

Antes de que entrara en vigencia la Ley de Identidad de Género, el cambio legal del nombre y sexo registrados por el Estado argentino requería de una acción judicial y una sentencia que la autorizara (Litardo 2010, 2012). El sometimiento de los/as sujetos/as trans a lógicas judiciales como condición para su reconocimiento implicaba -además de las dificultades propias del acceso al litigio legal para una comunidad ya marginada de la ciudadanía- la realización de pericias (médicas, psiquiátricas, psicosociales y psicológicas), la presentación de testigos y la comparecencia en audiencias. Un largo y costoso proceso que pocos/as podían enfrentar y que tenía una resolución incierta y siempre individual. Incluso cuando la sentencia era favorable, las pericias, los diagnósticos patologizantes, la exigencia de infertilidad y de modificación quirúrgica de genitales eran la norma.

Este panorama registra una ruptura alrededor del año 2010, cuando las demandas comenzaron a multiplicarse y el tenor de los fallos registró progresivos cambios. Ya no se requirieron cirugías de modificación genital y se otorgó el reconocimiento del Estado enmarcándolo en la lógica del derecho humano a la identidad de género, reduciendo o evitando las pericias y también los diagnósticos patologizantes (Cabral, 2012; Farji Neer, 2013). En ese momento histórico previo a la sanción de la Ley de Identidad de Género, tres de nuestras interlocutoras trans cambiaron sus datos personales en el DNI y en la partida de nacimiento a partir de fallos favorables en sendos recursos de amparo. Los tres fallos acontecieron entre 2011 y 2012, en el aparato judicial de la Ciudad Autónoma de Buenos Aires, una jurisdicción que fue especialmente receptiva a estas solicitudes y progresista en sus

Consejo Directivo de la Facultad de Filosofía y Letras de la Universidad de Buenos Aires (véase Radi, 2014). Luego, en 2011, la Universidad Nacional de Córdoba también dictó una resolución en el mismo sentido. Estas y otras resoluciones formaron parte de un proceso de apertura institucional y agitación política que precedió a la sanción de la Ley de Identidad de Género. 
resoluciones (Cardinaux, Clérico, Aldao y Ronconi, 2012). En todos los casos la resolución fue rápida en comparación con los trámites de otras épocas, y se realizó sin mediar requisitos de esterilidad ni de modificación quirúrgica de genitales. En dos de los tres casos la resolución fue expeditiva: bastó con la presentación de una historia de vida realizada por la demandante y se evitaron todo tipo de pericias. Además, uno de estos dos últimos casos se destacó por formar parte de una demanda colectiva que rompió con la lógica de la protección de un derecho individual para dar lugar al reconocimiento de los derechos de un colectivo. En el caso restante, correspondiente a Antonia (39 años), el trámite fue más largo porque se requirieron pericias, a pesar de que en su demanda se habían fundamentado las razones para negarse a ellas:

...hice todo para que no me patologizaran, tuve que pasar por las pericias porque era inevitable, porque si no, mi caso no salía (...) cuando llegué a la pericia los médicos forenses me vieron y me dijeron que no me iban a revisar, que aceptaban mi decisión de negarme a las pericias médicas (...) igual las pericias psiquiátricas y psicológicas las tuve que hacer todas, porque es parte del protocolo y de la rutina de cuando presentás un amparo (...) se hace un diagnóstico pero lo mismo que en las otras pericias, hacen un informe basado en un diagnóstico ocular, digamos... no me hicieron desvestir ni nada pero me vieron e hicieron su informe, más los informes psiquiátricos y psicológicos, hicieron un informe y después pidieron que me haga unos estudios porque consideraron que era necesario...

La claridad y la fortaleza de Antonia para resistirse a la patologización ("hice todo para que no me patologizaran") surge de su alianza con un entramado de activismos emergentes de una necesidad política vital: no seguir sometiendo al propio cuerpo y a la complejidad de las experiencias trans a la evaluación médica que solo puede concebirlos en tanto desvío y anormalidad. El relato acerca de su trámite muestra cómo, en esos años, el Poder 
Judicial se fue haciendo de a poco más receptivo a las demandas de las personas trans ("los médicos forenses me vieron y me dijeron que no me iban a revisar, que aceptaban mi decisión de negarme a las pericias médicas"). Sin embargo, el relato de Antonia también muestra que no pudo evitar del todo su objetualización en las tramas del poder jurídico-médico. Aunque el "diagnóstico" sea calificado ahora como "informe", ella fue sometida a escrutinio. Las pericias psiquiátricas y psicológicas, en especial, se presentan como algo inevitable dentro de una "rutina" y de un "protocolo" que performativamente no hace sino recolocar la demanda ciudadana en el ámbito de la salud mental y reforzar la autoridad de esa disciplina para producir saberes autorizados acerca de las personas trans. Lo visto por el ojo médico ("los médicos forenses me vieron", hicieron un "diagnóstico ocular", "me vieron e hicieron su informe") conserva su poderío. Se trata, en conjunto, de un sometimiento mermado al poder jurídico-médico que es aceptado por ella en aras de un objetivo superior: ser reconocida por el Estado con su nombre y su género ("era inevitable, porque si no mi caso no salía").

Nuevas posibilidades y futuros se abren a partir del reconocimiento estatal del nombre propio y del género. En el relato de Valeria (35 años), quien obtuvo su reconocimiento por medio de una acción de amparo, la posesión del DNI con su nombre desencadena lo que ella percibe como una transformación en su vida. Lo imposible se hace imaginable y lo que se solicitaba, cada vez, como una concesión, se podrá ejercer como un derecho que la equipara con el resto de las ciudadanas:

Yo ahora puedo acceder a un hospital público y ponerme en lista de espera para hacerme la intervención de prótesis mamaria gratuitamente (...) ahora que tengo documento y que no me tengo que exponer al obstáculo de pedirle al profesor el favor de que no me pongas el nombre [de varón], por favor, tachame, poneme Valeria... y tal vez para tener otra posibilidad de salida laboral, pensé en seguir estudiando y ser maestra (...) ahora soy como cualquiera, 
traguen saliva chicos y chicas, voy a ser la maestra Valeria...

En el relato de Valeria, el ser reconocida por su nombre le abre posibilidades en diversos ámbitos de la vida social: con respecto a su salud integral y a su cuerpo, al trato digno que podrá recibir en las instituciones y a nuevas oportunidades laborales. Ser reconocida por su nombre la iguala ("ahora soy como cualquiera") con el resto de los ciudadanos y ciudadanas que tienen el privilegio naturalizado de ser reconocidos por el nombre y el género que sienten como propio.

La lógica del reconocimiento del derecho a la identidad de género mediante el amparo judicial tenía serias limitaciones, dificultades y riesgos: grandes esfuerzos (en términos de recursos económicos, sociales, culturales, o de tiempo) se llevaban adelante con un resultado incierto que podía incluir en la patologización de la identidad y en el requisito de modificaciones corporales, entre otros inconvenientes. Además, las resoluciones se limitaban al caso, y por lo tanto el acceso igualitario y respetuoso a la identidad de género para toda la comunidad trans en tanto colectivo podía provenir sólo de una ley acorde a las luchas sociales que se estaban desarrollando.

Aunque la Ley de Nombre continúa imponiendo esa coherencia para las criaturas recién nacidas y el régimen identitario de los géneros permanece todavía como una dicotomía donde solo dos posiciones son posibles, la sanción de la Ley de Identidad de Género en 2012 rompió de manera definitiva con el paradigma sociojurídico que asociaba indisolublemente el nombre de pila con el género y el sexo de la persona. Se trata de una ficción reguladora mucho más flexible que reconoce y posibilita una multiplicidad de diferencias porque el sexo ya no se alinea con fuerza de necesidad con la identidad de género. La ley iguala también a la ciudadanía en sus derechos, y abre, de maneras muy concretas, oportunidades de vida para las personas trans.

Varias de las entrevistadas trans que ya habían modificado su DNI por las vías administrativas que prevé la Ley de Identidad 
de Género, al momento de realizar la entrevista se encontraban adecuando otros documentos, certificados, títulos educativos y de propiedad para tenerlos "a su nombre". Para todas ellas, ejercer el derecho a tener la documentación identificatoria estatal que acredite su nombre y, al mismo tiempo, su identidad de género, se anuncia como la posibilidad de ejercer otros derechos ciudadanos fundamentales (a la educación, a la propiedad, al trabajo, a la salud, etc.) que se volvían abstractos y de difícil cumplimiento cuando la identidad de género de las personas trans no era reconocida por el Estado.

\section{Recapitulación: hablas generizadas, nombres propios y reconocimiento social}

El análisis presentado hasta aquí mostró que la incesante utilización de desinencias gramaticales femeninas en el discurso autorreferencial produce performativamente la ilusión de un género femenino sustantivo y permanente. Aun cuando las feminidades trans y no trans se producen mediante las mismas estrategias discursivas, la producción de las feminidades no trans en el lenguaje resulta socialmente legitimada y naturalizada. En cambio, las feminidades trans son ubicadas en una posición socialmente marcada que las expone con frecuencia a distintos tipos de rechazo y violencia social. Para las personas trans, el género gramatical constituye muchas veces un espacio de lucha por el reconocimiento, pero también de falta de reconocimiento, cuando es experimentado como una imposición violenta de otros/as sobre el más básico sentido de sí mismas.

La rigidez del binario lingüístico es por momentos desafiada en el discurso de las feminidades trans, donde es posible localizar modos de experimentación novedosos que tensionan la normativa lingüística del género, por ejemplo, mediante la creación de posicionamientos neutros que evitan la utilización de determinantes de género o de la creación de posiciones que no responden a las convenciones binarias de la lengua. 
En cuanto al nombre de pila, se sostuvo que la acción repetida de ser nombrado y de nombrarse también produce performativamente el género de los sujetos. El nombre se encuentra regulado por severas convenciones socioculturales y legales que exigen una relación obligatoria entre el sexo asignado al sujeto y el género de su nombre. En la Argentina, hasta la sanción de la Ley de Identidad de Género en 2012, el Estado identificaba e interpelaba a todos los sujetos con el nombre que anudaba sexo y género de manera obligatoria durante toda su vida. Dicha regulación legal de los nombres y las identidades instalaba una palmaria desigualdad entre las personas no trans quienes podían ser identificadas y reconocidas en todo momento con el nombre y el género que sentían como propio- y las trans quienes, en general, no eran reconocidas por el nombre y el género que sentían como propio-. Esta situación marginaba a las personas trans de los derechos ciudadanos más básicos y, al mismo tiempo, las exponía a situaciones de maltrato en las cuales derechos ciudadanos fundamentales se volvían abstractos y de difícil cumplimiento.

El análisis presentado muestra que el sexo asignado resulta insuficiente para dar cuenta de las variadas maneras de vivir el género, que el género no es un atributo fijo, y que en el habla cotidiana -a través del uso de los nombres y del género gramatical- se disputan cuestiones claves relativas al reconocimiento y la dignidad humana. Los grandes avances ocurridos en la Argentina en lo relativo al reconocimiento social y la protección legal de los derechos de las identidades trans se encuentran en el tiempo presente asediados por enérgicas reacciones culturales conservadoras que, en el mejor de los casos, buscan reducir el alcance de ese reconocimiento a una mera tolerancia de la diferencia. El efecto de estas derivas conservadoras del reconocimiento es la reificación de esas diferencias y el reforzamiento de las jerarquías entre personas trans y no trans. Frente a este panorama, el desafío es defender los derechos conquistados y, a la vez, no abandonar una relación 
crítica con las formas siempre excluyentes de reconocimiento que puede proveer la ley.

\section{Referencias bibliográficas}

AultmAN, B. Lee. Cisgender. TSQ: Transgender Studies Quarterly, vol. 1, no 1-2, Durham, 2014, pp.61-62.

BERKINS, Lohana (comp.). Cumbia, copeteo y lágrimas. Informe nacional sobre la situación de travestis, transexuales y transgéneros. Buenos Aires, Asociación de Lucha por la Identidad Travesti-Transexual, 2007.

BERKINS, Lohana; FERNÁNDEZ, Josefina (coords.). La gesta del nombre propio. Informe sobre la situación de la comunidad travesti en la Argentina. Buenos Aires, Ediciones Madres de Plaza de Mayo, 2005.

BUTLER, Judith. El género en disputa. El feminismo y la subversión de la identidad. Buenos Aires, Paidós, 2007 [1990].

. Cuerpos que importan. Sobre los límites materiales y discursivos del "sexo". Buenos Aires, Paidós, 2005 [1993].

. Lenguaje, poder e identidad. Madrid, Síntesis, 2004 [1997].

Cabral, Mauro. Cisexual. Suplemento Soy, Página/12, Buenos Aires, 5 de junio de 2009 [https://www.pagina12.com.ar/diario/suplementos/soy/1-803-200906-12.html - acceso 29 nov. 2015].

. Algo ha pasado. In: MORÁN FAÚNDES, José Manuel; SGRÓ RuATA, María Candelaria; VAGGIONE, Juan Marco (ed.). Sexualidades, desigualdades y derechos. Reflexiones en torno a los derechos sexuales y reproductivos. Córdoba, Ciencia, Derecho y Sociedad, 2012, pp.251-273.

. Cuestión de privilegio. Suplemento Soy, Página/12, Buenos Aires, $\quad 7$ de 2014 [http://www.pagina12.com.ar/diario/suplementos/las12/13-86882014-03-07.html - acceso 29 nov. 2015].

CARDINAUX, Nancy et alli. Hacia la reconstrucción de un perfil de juez/a permeables a las demandas de identidad de género: el caso del 
contencioso administrativo tributario de la ciudad de Buenos Aires. Ambiente jurídico, $\mathrm{n}^{\circ}$ 14, Manizales, 2012, pp.16-35.

COMISIÓN Provincial por La Memoria. Registro nacional de casos de tortura o malos tratos. Informe anual 2011. Buenos Aires, Comisión Provincial por la Memoria, 2012.

- Registro nacional de casos de tortura o malos tratos. Informe anual 2012. Buenos Aires, Comisión Provincial por la Memoria, 2013.

ENKE, A. Finn. The Education of Little Cis: Cisgender and the Discipline of Opposing Bodies. In: ENKE, A. Finn (ed.). Transfeminist Perspectives in and beyond Transgender and Gender Studies. Philadelphia, Temple University Press, 2012, pp.60-77.

FARJI-NEER, Anahí. Fronteras discursivas: travestismo, transexualidad y transgeneridad en los discursos del Estado argentino, desde los Edictos Policiales hasta la Ley de Identidad de Género. Tesis (Maestría en Investigación Social), Facultad de Ciencias Sociales, Universidad de Buenos Aires, 2013.

FERNÁNDEZ, Josefina. Cuerpos desobedientes. Travestismo e identidad de género. Buenos Aires, Edhasa, 2004.

FoucAult, Michel. Historia de la sexualidad. Tomo 1, La voluntad de saber. Buenos Aires, Siglo XXI, 2008 [1976].

FRASER, Nancy; BuTLER, Judith. ¿Reconocimiento o redistribución? Un debate entre marxismo y feminismo. Madrid, Traficantes de Sueños y New Left Review en Español, 2016.

García Negroni, María Marta. Escribir en español. Claves para una corrección de estilo. Buenos Aires, Santiago Arcos, 2011.

Honneth, Axel. The Struggle for Recognition: The Moral Grammar of Social Conflicts. Cambridge, The MIT Press, 1995 [1992].

LITARDO, Emiliano. Los derechos sexuales y derechos humanos: aproximaciones sobre la (trans) judicialización. In: PAUTASSI, Laura (org.). Perspectiva de derechos, politicas públicas e inclusión social. Debates actuales en la Argentina. Buenos Aires, Biblos, 2010, pp.221260. 
. Escupamos sobre Júpiter. Filosofía del derecho, $\mathrm{n}^{\circ} 1$, Buenos Aires, 2012, pp.147-171.

. Los cuerpos desde ese otro lado: la ley de identidad de género en Argentina. Meritum, vol. 8, n 2, 2013, pp.227-255.

LITARDO, Emiliano; RADA SCHULTZE, Fernando. El género identificado o las marcas de la identificación del género. Ponencia presentada en el III Seminario Académico de Género y Diversidad Sexual del Uruguay, Facultad de Ciencias Sociales, Universidad de la República, 2010.

Moreno, María. Políticas del nombre. Suplemento Soy, Página/12, Buenos Aires, 18 de noviembre de 2016 [https://www.pagina12.com.ar/3829-politicas-del-nombre - acceso 12 enero 2015].

RADI, Blas. Sobre la perspectiva de géneros en la universidad. Ponencia presentada en el panel Educación y sexismo la formación universitaria de las Jornadas Degenerando, Facultad de Filosofía y Letras, Universidad de Buenos Aires, 2014 [https://www.aacademica.org/blas.radi/2 - acceso 12 enero 2017].

SABSAY, Leticia. Los dilemas del antiesencialismo en la teoría feminista contemporánea: una reflexión en torno a Judith Butler. Almería, Instituto de Estudios Almerienses, 2007.

Serrano, Julia. Dismantling Cissexual Privilege. In: Serrano, Julia. Whipping Girl. A Transsexual Woman on Sexism and the Scapegoating of Feminity. Emeryville, Seal Press, 2007.

Spade, Dean. Normal Life. Administrative Violence, Critical Trans Politics and the Limits of Law. New York, South End Press, 2011.

STRYKER, Susan. Transgender History. Berkeley, Seal Press, 2008.

TAYLOR, Charles. The Politics of Recognition. In: GutMAnN, Amy (ed.). Multiculturalism: Examining the Politics of Recognition. Princeton, Princeton University Press, 1994, pp.25-73.

VACAREZZA, Nayla Luz. Feminidades en la encrucijada de los estilos corporales y las categorías identitarias de género y sexualidad. Tesis (Doctorado en Ciencias Sociales), Facultad de Ciencias Sociales, Universidad de Buenos Aires, 2015. 
WAYAR, Marlene. No estamos todxs, faltan lxs trans presxs. In: COMISIÓN Provincial por La Memoria. Registro nacional de casos de tortura o malos tratos. Informe anual 2011. Buenos Aires, Comisión Provincial por la Memoria, 2012, pp.193-194.

WitTig, Monique. La marca del género. In: WitTiG, Monique. El pensamiento heterosexual y otros ensayos. Madrid, Egales, 2006, pp.103-116 [1992]. 